\title{
Global Community Development Village Network: An Interdisciplinary International Service Learning Model
}

\author{
Thomas Soerens \\ Associate Professor, Department of Civil Engineering \\ University of Arkansas \\ Fayetteville, AR 72701 \\ tsoerens@uark.edu \\ Carol Gattis \\ Associate Dean, Honors College \\ Associate Professor, Department of Industrial Engineering \\ University of Arkansas \\ Fayetteville, AR 72701 \\ $\operatorname{csg} @$ uark.edu
}

Abstract - In the summers of 2007, 2008, and 2009 the University of Arkansas (UA) sent 148 students to Belize for a month to perform service projects as part of a new service learning program in developing countries. During the spring semester, the students enrolled in an interdisciplinary lecture course team-taught by 9 faculty members plus a discipline-specific practicum held on the UA campus. The subsequent summer session was spent in the Dangriga, Belize vicinity with students implementing their service projects developed during the spring semester practicum. Each year eight student teams implemented approximately 12 projects in different disciplinary areas. The UA partnered with Peacework, an international NGO with a long-time presence in Belize and initiatives in many countries worldwide and committed to a minimum of 5 years for projects in Dangriga. The partnership utilized the "village network" concept where these partners worked with the Dangriga community leaders to determine the multifaceted efforts needed to have a broad and positive impact on the community. The UA placed administrative staff in Dangriga during the academic year to develop and maintain contacts and provide legwork and on-site organization for the projects. Projects dealt with microfinancing, small business consulting, literacy, social work, hygiene education, water systems, protected area management, school farms, and education. The program faced, and continues to face, a number of challenges, such as coordinating and administering a multidisciplinary program, securing financing, ensuring academic rigor, and providing logistics. In spite of the challenges, the program was overwhelmingly successful, changed students' lives, and received good community feedback. The UA and Peacework hope to expand the program to other countries. The UA Belize study abroad program, featuring an interdisciplinary, long-term, community partnership between $U A$ and Dangriga, offers a challenging but promising service-learning model.

Index Terms - Interdisciplinary, multi-disciplinary, service-learning, engineering education, Belize, protected areas, community development. 


\section{The need for the Program}

The value of service-learning in higher education is well established. Engineering projects in developing countries as senior design experiences, for example (Phillips et al., 2007; Padmanabhan and Katti, 2002), offer valuable cultural and technical experiences for engineering students. Two ways to make these experiences more valuable for the students, the community, and the university are to 1) establish a long-term partnership with the developing community (Duffy, 2008) and to 2) involve a more interdisciplinary student and faculty team (Mihelcic et al., 2007). Educators also need to clarify the goals and motivations underlying the servicelearning (Kahn and Westheimer, 1996).

In the summer of 2009, the University of Arkansas (UA) sent an interdisciplinary group of 42 students from several colleges and many departments to the community of Dangriga, Belize for four weeks to participate in service learning projects with the local community. In its third year of a new "global community development" program, the program is run through UA's Global Campus' Study Abroad Office and is facilitated by Peacework, an international NGO. The Dangriga/UA partnership is the initial "Peacework Village Network" program partnering universities with developing communities (see Peacework.org). A spring on-campus course, HUMN 425 Community Development in a Global Context, is a prerequisite for the summer study abroad experience. The spring course is a team-taught lecture course, students from all disciplines participate together in the classroom discussions and assignments. During the spring, students also divide into project practicum teams primarily, but not exclusively, by discipline to plan and develop their summer projects. Peacework and UA have staff in Dangriga during the academic year to organize projects and maintain relationships with the community. Following is an overview of the program from its inception through today.

\section{History - Initiation of the Program}

In 2005, Peacework and UA representatives began discussions on developing a new service learning model based on the Peacework village concept. The UA wanted to provide an interdisciplinary service learning experience for honors students that would truly impact a community, provide academic degree credit, and involve all UA academic colleges offering undergraduate degree programs. The resultant model presented below spans five academic colleges (all except architecture). The program founders included the director of UA study abroad, a faculty member and director of international programs in engineering, a faculty member and associate dean in the college of arts and sciences, the assistant dean for the honors college, and alumnus Stephen Darr of Peacework. Peacework is an NGO with offices in Virginia and Prague. Darr and his staff place students and faculty from a number of American universities and corporate volunteers in service projects in 34 countries around the world (Peacework.org). Once the concept was developed and the country was determined, the founders identified additional key faculty in the colleges to further develop the concept and, eventually, the academic courses and delivery of this community development program. Belize was selected as this US based service-leaning program location because its people speak English; the travel is relatively uncomplicated, convenient and safe; and its culture and organizational infrastructure there are welcoming to these type projects.

The initial site visit in 2006 to three prospective locations in Belize included UA key faculty and Peacework representatives. The site visit principal goal was to identify a Belizean 
community with which we could partner in our service learning projects and a site which be suitable for bring a group of students. After visiting several towns, Dangriga, a city of about 15,000 on the coast of the Caribbean, was chosen. Dangriga is called "the cultural capital of Belize," and is a fascinating mixture of Creoles, Mestizos, and Mayans, although it is dominated by the Garifunas, a Caribbean people descended from African slaves and indigenous groups. Dangriga offers facilities to house the students, partnerships with schools, and many opportunities to collaborate with the local community in development.

The UA Honors College and the academic colleges provided funding in summer 2006 to establish the Community Development program, and UA and Peacework made a 5-year commitment for Dangriga community projects. In fall 2006, two recent UA grads, cofunded by UA and Peacework, moved to Dangriga to build relationships and provide on-site legwork before and during project implementations. The faculty team traveled to Dangriga in October 2006 to facilitate the upcoming projects.

\section{Program}

\section{Spring Course 2007}

In January 2007, the first course, an interdisciplinary three-hour course, entitled "HUMN 4253 Community Development in a Global Context: An International Service Learning Program," was team taught. The goal of this course was to introduce students to developing communities, in particular, Belize.

Belizean subject matter, such as the nation's history, languages, race relations, infrastructure, social structure, health system, agriculture, politics, economics, and ecology was presented. General development material was also presented in economic, agricultural, engineering, and other contexts. For example, several class periods were spent on sustainability and how it relates to international development and to Belize. In addition to the faculty, invited speaker Steve Darr of Peacework challenged the students to avoid the word "help" and instead think of partnering with the community to accomplish their goals.

Assigned readings included a recent social and political history of Belize (Thomson, 2005), and articles chosen by the teaching team, including community development, Belize and its neighbors (Hartshorn, 1984), and service learning (Eman, 2006). In addition, honors students were instructed to write a paper on either the Sachs (2005), Easterly (2006), or Kidder (2003) book. Specific readings for engineering students included 2006 UNDP Human Development Report (UNDP, 2006) and service-learning reading (e.g., Pearce, 2006).

Each teaching team member delivered lectures relating her or his field in the context of Belize, with the instructor of record responsible for ensuring continuity and encouraging understanding of the relationships among the various perspectives offered by the team. Each teaching team member attended class the entire semester and participated in the ongoing conversation.

In addition to the lecture class, students formed practicum teams to develop and plan the community development projects to be implemented in summer. The projects were divided by discipline; however, some students participated in a project from a different discipline than their own. The engineering-lead public health project team had 13 primary student members -11 from Engineering (including Civil, Biological, Chemical, and Mechanical Engineering), one from Architecture and one from Business. While the students were assigned individual tasks for 
the team matching their skills and interests, they were also challenged to learn more by participating in other tasks.

The practicum involved technical learning and design, materials ordering, and fundraising. During Spring Break, a faculty member and three students visited Dangriga to further establish contacts and initiate project set up.

In the initial planning process, the practicum was designed to be a one hour lab class in addition to the lecture class. However, discussions with prospective students revealed that students felt the one-hour course would not fit a slot in their schedules, so they preferred to work on the project without paying for an extra credit hour. Although, the practicum work is done outside of class lecture time, it does not have a course number or credit associated with it. Students may enroll in the spring course without going to Belize in the summer, but they cannot register for the summer courses in Belize without haven taken the spring course.

\section{Summer Program 2007}

The faculty and student teams spent four weeks in May/June 2007 implementing their projects in Belize. The UA Office of Study Abroad administered the summer program in cooperation with Peacework, which facilitated all in-country arrangements. Faculty and students from different disciplines shared breakfast and dinner together and performed their different projects throughout the community during the day. Meetings of the whole group were held on Wednesday evenings. There were regular informal meetings between the different teams and different groups as they helped each other on projects. For example, the engineering team assisted with the agriculture team's school farm project and all teams worked together on a trash pickup organized by a business team.

For the discipline-specific project course, the faculty member for a given discipline was responsible for the specific syllabus, assignments, and grading for that course. Engineering students received 3 semester hours of engineering special problems credit and 3 hours of humanities credit. All of the students who registered for engineering credits in the summer were engineering students. The students from other disciplines received 6 hours of credit within their disciplines. Of the 74 students enrolled in the spring course, 55 enrolled in the summer courses and went to Belize, including all 12 of the engineering students.

The engineering team in 2007 focused on three projects: public health education and surveys in Bella Vista, water system construction for Steadfast, and surveying in Dangriga. Bella Vista, one hour's drive from Dangriga, was identified by Belizean officials as having a high incidence of waterborne diseases; however after a site visit, it became clear that their major issues were financial and political rather than technical. This combined with a lack of sufficient funding to setup major infrastructure in Bella Vista forced the project team to focus on health education and health surveys in Bella Vista. The health education was conducted by students in Spanish, the main language of the village (Belize is English-speaking in general). Subsequent work facilitated by Peacework in Bella Vista involved graduate students from the Clinton School for Public Service following-up on the health education, as well as a team from Virginia Tech, who obtained funding and constructed major water system improvements in Bella Vista in 2008.

The village of Steadfast is 15 miles from Dangriga. A community group in the village, the Steadfast Tourism and Conservation Authority (STACA), established and manages Billy Barquedier National Park on pristine land next to the village. Steadfast and the neighboring community of Alta Vista get their water from Billy Barquedier Creek in the park. The water is 
piped untreated by gravity to the villages. Although anecdotal evidence suggests that there is not a high incidence of waterborne diseases in the villages, muddy water created during rains is a nuisance and, therefore, the community asked for filtration of the water. STACA, with UA's participation, obtained funding from the Belize Protected Areas Conservation Trust (PACT), the agency that oversees Belize's protected areas, for construction of a water filtration system. With two student teams working together (the engineering and ecology teams), they constructed a system using rapid sand filters. The system was undersized, however, due to a vast underestimate of the village's water use (over 100 gallons per person per day). This usage is equivalent to consumption in the US and is inconsistent with the literature value for a developing community, which is about 10 gallons per day (Weight, 2008). In addition, the ecology team performed park wildlife surveys and helped develop the park's management plan. Strong and ongoing friendships were built between UA faculty and students and the STACA members.

One team, led by a student experienced in surveying, addressed Dangriga's road flooding during rains and accumulated standing water locations, as requested by Dangriga's mayor. The team surveyed several roads and neighborhoods to assist Dangriga in drainage planning.

The agriculture team planted a large pepper garden at St Matthews School in Pomona, a community just outside of Dangriga, so the school could sell the peppers to raise school funds. Business teams consulted with local businesses to develop business plans and started a microloan program for students who could not afford secondary school. In Belize, families must pay a fee for secondary school. The team also worked closely with the mayor's office on tourism planning and trash cleanup. The Social Work team held workshops for women's groups and schools on topics such as self-esteem and family violence. The Literacy team helped teachers learn techniques to better teach English reading (most students speak Creole at home) and helped students improve their reading skills through classroom and in-home projects.

Each team wrote an executive summary about what they accomplished during the time in Belize and this report was given to the mayor of Dangriga. The mayor, who has since stepped down as mayor and is currently a graduate student in Public Administration at UA, credits this report for giving him data and justification to initiate a tourism program that was funded by the national government.

On two weekends, the students were evenly divided into two travel groups to participate in organized alternating excursions. One weekend, they visited Caye Caulker island for sun, diving, snorkeling, and other water sports. The other weekend, they traveled to San Ignacio for caving and river adventures and to visit Mayan ruins. During the third weekend, students enjoyed free time, and many chose to stay at Placencia, a beach area where many Americans live and vacation. During that weekend, T. Soerens and select ecology students participated in a workshop in Steadfast on watershed issues.

The summer program student cost was $\$ 3600$ plus tuition. Honors scholars had scholarships to cover this cost and a limited number of other Study Abroad scholarships were available. Some students received scholarships from their departments. For other students, however, the cost is a major barrier. It would be desirable for the program to have the funding to disperse its own scholarships to cover deserving students who do not receive other scholarships. 
The summer experience received overwhelmingly positive reactions from the students and the community. Although there were inevitable changes in the planned projects, all were pleased with the projects and outcomes. Except for minor issues of sunburn, insect bites, and intestinal problems, the students stayed safe and healthy. A purse-snatching at midnight on the last night in Belize marred an otherwise crime and conflict free experience. Several students reported lifechanging experiences, and one student joined Peacework as an intern, saying the experience changed her life.

In evaluating the summer experience, one issue was inconsistency among the teams in the writing and reporting requirements, partly due to the diverse nature of the projects. Some teams had extensive individual writing assignments while others had only the final project executive summary writing requirement. To improve the course and provide consistency for the future, faculty traded syllabi and discussed ideas for the future. To ensure continuation and sustainability of the projects, one student was assigned to follow-up on all the projects and maintain a sustainability binder for each team.

As mentioned, UA had staff (recent graduates) in place in Dangriga from fall of 2006 through spring 2007, after which they began graduate school. With relationships and projects more established, costs were saved by waiting until spring 2008 to send new staff to Dangriga. In the interim, e-mail communication and Peacework staff were relied on for any interactions and arrangements during fall 2007.

The UA Provost gave a one-time funding contribution to maintain the program for another year, which added to the academic colleges' financial support.

\section{Program}

\section{Spring course}

The major change in the spring course from 2007 to 2008, based on assessment of the spring 2007 course, was the shortening of several lectures to allow class time for project meetings. This better unified and prepared the teams for the summer experience and provided a more wellrounded interdisciplinary experience. For the engineering and ecology teams, in addition to the common readings, students were assigned lessons to prepare them for the planned water quality monitoring study in the summer. Students also examined the UN Millennium Development Goals and applied them to their projects. An effort was also made to connect ecological work in Belize's protected areas to development (DeClerck, 2006). Table I shows an example of a student assignment, and Table II shows exam questions.

In 2008, the capacity of UA for academic service-learning was enhanced through faculty development by courses completed by faculty in this program. Laura Gray, instructor in English, completed an on-line course through West Virginia University, SRVL 695 Introduction to Global Service-Learning Pedagogy, Preparation, and Research (instructors Eric Hartman and Richard Kiely). In addition to service-learning theory and pedagogy, the course examined how to integrate community-based research into service-learning course. Laura Gray assumed much of the organizational load of the 2008 UA Community Development class and was the instructor of record. Thomas Soerens accepted a quarter-time appointment from the Provost to evaluate 
service-learning on campus and around the country, and he completed Campus Compact's Professional Development Institute for Service-Learning Professionals in 2008.

\section{Summer}

Most projects in 2008 were continuations of 2007 projects. The agricultural project continued work with the school farm in Pomona, but planted different crops. Peppers the previous year were not very profitable, because the peppers matured during the summer school break and were picked by neighbors rather than the school. Therefore, the team planted food crops that could be used by the school, including okra, bell pepper, carrots, tomatoes, cabbage, and radishes. The goal was to see which crops would thrive and would provide food for school lunches. The business teams again worked with the mayor's office and other teams worked with the schools, building on existing relationships.

Another result of the previous year's program was visually obvious - the city of Dangriga had less trash lying around and looked cleaner. The efforts of the business team to install public trash cans and discourage littering had a noticeable effect.

The engineering team worked again with Billy Barquedier National Park and Steadfast. STACA, with UA's participation and showing UA's student and faculty time as in-kind matching funds, was able to obtain a grant from PACT to build a compost toilet and changing facility in the park. The engineering and ecology teams, led by a student with extensive experience in construction, worked together to construct the building. The team also built a thatch camp building ("palapa") on the park's back side, which required hiking two hours into the jungle and camping overnight; it was very popular with the students. The engineering team also surveyed selected newer neighborhoods in Dangriga, establishing elevations for drainage planning.

Another engineering project involved water quality monitoring of the North Stann Creek watershed, which includes Billy Barquedier Creek and the North Stann Creek, which empties into the ocean at Dangriga. This project supported ongoing monitoring by STACA and contributed to ongoing environmental protection measures in the area. Nutrient samples were taken and analyzed by UA's Water Quality Lab, and biological samples were analyzed by Dr. Ed Boles, a Belizean biologist. The sampling task was lead by a student with experience in water sampling for UA researchers.

UA sent a reporter to follow and report on the program in Dangriga for one week and a videographer for the full four weeks of the program. A 15 minute and a two minute program video were produced.

A major issue encountered during the summer 2008 experience was massive flooding due to tropical storm Arthur. The storm flooded roads, washed out bridges, severely damaged 250 homes in the Dangriga area, and shut down the town for several days. Stann Creek valley was declared a disaster area. Most tragically, in Valley Community, next to Steadfast, a family's home was washed away and the family was killed. The intake for the Steadfast water system, a small concrete dam in the creek, and the first mile of pipeline were destroyed. The Caye Caulker student excursion was cancelled as the storm approached, and all students were taken to San Ignacio, returning June 1 when the most severe flooding hit. With roads in and surrounding the town under water, schools were shut down. In addition to this, government agencies were busy dealing with emergencies, so the student projects had to be put on hold. 
Students responded to the storm by volunteering at the Red Cross and at other relief agencies. They distributed food and water, cleaned an emergency shelter to receive people, gathered donations, and assisted in other ways. Most students elected to stay in Dangriga on their "free" weekend to continue assisting relief efforts. The National Emergency Management Agency of Belize (NEMO) donated new pipeline to Steadfast, and the engineering team worked with community members to reinstall the pipeline.

Upon returning to the US, the students had two weeks to complete papers as part of their classes. Engineering students prepared an executive summary of the program and technical reports of each project. In addition, each student wrote a paper applying the methodology of McConville and Mihelcic (2007) to assess project sustainability through life-cycle analysis. Throughout the summer project, students were required to keep journals of their experience, although the journals were not read by the instructor. For the humanities class, the students were required to write a paper on what they learned about the culture and civilization of Belize and were encouraged to reflect on their journal writings to produce the paper.

In the assessments, students and community members reported positive experiences that greatly benefited them. One engineering student later assembled a senior design team to expand and enhance the Steadfast water system. Another student, with little interest prior to the Belize program, joined an international development program.

\section{Program}

For the 2009 program, the administrative structure of the program needed to be changed to ensure its sustainability. Amy Farmer, professor of economics, was appointed program director and given class release time. An executive board, consisting of Thomas Soerens and the academic colleges' associate deans was created. Dr. Farmer and the board met with various upper-level administrators, development officers, and outside interested parties to promote the program and seek advice. The Office of the Provost and the academic colleges continued program financial support.

The program saved costs by shortening the staff time in Dangriga. In 2009, a UA student and a Peacework staff member were sent to Dangriga in March, two months later than the previous year, to coordinate work on the projects.

The spring 2009 lecture class, taught primarily by Laura Gray, included more general material on development. More in-class discussion and interaction was added. Assigned materials included the deliberately provocative, like "To Hell with Good Intentions" (Illich, 1968) and "How to Rule the World" (de Guillaume, 2003), as well as additional service-learning literature (e.g., Camacho, 2004).

A Biological Engineering senior design team, including a Belize 2008 participant, worked with the 2009 Belize team to design and plan expansion and improvements to the water treatment system built for Steadfast in 2007. This was the engineering team's primary project for 2009, along with rebuilding the intake structure destroyed by the 2008 storm. The senior design team pursued and obtained project funding from corporate partners. One of the graduating senior design students, although not officially part of the study abroad program, obtained funding from the Biological Engineering department to spend a month in Belize assisting the students in implementation of the water system project. 
All teams were required to develop quantitatively measureable project assessments. The measureable assessments of the engineering project are the water treatment system flow capacity and the removal of bacteria by the system.

\section{Challenges and Conclusions}

Funding remains a critical challenge. Although the study abroad fees and tuition paid by the students in the program provides the main source of funding, this does not cover the ongoing program expenses, particularly the needs throughout the year. These costs include the UA and Peacework staff in Dangriga prior to the summer implementation plus faculty and student travel to Belize during the academic year. Although funding from the Provost's office and the colleges have funded these costs and faculty summer salary, sustained dependable funding is needed, particularly considering the current economic situation. The university and college development offices are seeking additional funding and are hopeful of sponsorship to fund the program on a long-term basis.

A key to program continuity has been the staff presence in Dangriga prior to the summer to set up the projects. Of course, a partner in the country is necessary to any study-abroad program, especially one that involves community development projects. Another vital key is having an incountry facilitator, such as Peacework, who initiates and facilitates the program.

The program goal is to develop an ongoing partnership between the community of Dangriga, Belize, Peacework and UA to provide an excellent interdisciplinary service learning experience for students. This new Peacework Village Network model was described by Peacework in this way (Peacework, 2009):

"The Village Network focuses on the partnership of ONE Community with ONE sponsoring Institution, collaborating across disciplines. Students and faculty from partnering institutions use their resources and expertise in each of their specific disciplines to work with community leaders and grassroots organizations familiar with local needs and resources. This novel approach creates more effective and sustainable projects and builds applicable cross-disciplinary educational opportunities and collaboration within the university setting. Ostensibly, these efforts then serve as a catalyst for regional development and cooperation."

The Peacework Village Network concept is very similar to the vision expressed by Duffy (2008):

"The long term vision is to have a whole university partner with networks of villages to address the many community needs and the learning needs of students in many disciplines in a sustainable way."

The interdisciplinary or meta-disciplinary aspect of the program was among the most valuable program contributions, and was emphasized throughout the course. For example, in lectures on water and sanitation, it was stressed that virtually everyone in the world who has money has clean water and adequate sanitation. Thus, economic development and water and sanitation infrastructure are interrelated. The different teams combined on many activities and tasks during the summer. There remains, however, a challenge to better integrate the teams in the planning, 
assessment, and implementation stages of their projects. One future goal is to become a more meta-disciplinary program (Mihelcic et al., 2007; Paterson et al., 2006; Hokanson et al, 2007).

Another issue is the integration of upperclassmen and lowerclassmen. The first two years, the engineering team had mostly upperclassmen, and their technical knowledge and maturity were important for accomplishing the projects, including some with academic and work experience relevant to our projects. In the third year (2009), having a recent graduate lead the students was critical to implementation of the project. There are advantages, however, to involving underclassmen. Involving underclassmen better engages them with the university, promotes involvement in student organizations, such as Engineers Without Borders, and provides them better vision for planning their future. In 2009, most students in the course were underclassmen, which differs from previous years. Since the engineering course is upper-level, there is some questioning from the departments as to whether underclassmen are academically prepared for an upper level class and whether they should receive upper-level credit for the project work. One underclassman was asked by her department to keep a technical journal to document that her technical work deserved upper-level credit. The students performed water system hydraulic analysis and their water system technical report satisfied the departmental requirements. Overall, the vertical integration of different year students is positive for all students, but it presents challenges. At this point in time, the need to sustain the program financially and meet enrollment necessitates acceptance of underclassmen to create a team of at least 7 or 8 students. Also, in the first three years of this program, upperclassmen were more likely than underclassmen to cancel out of the Belize summer component due to work or family obligations.

Discussions on improvements to the spring course include increased cross-discipline collaboration, removal of logistic obstacles, summer program participation, and ways to involve students from other universities, perhaps through the SEC Academic Consortium (SECAC) or other venues.

The flood in 2008 emphasized a perhaps unavoidable problem in the timing of the program, which begins after the end of the UA spring semester. The rainy season in Belize usually begins around June 1, providing only two weeks before the rains start. In 2007 and 2009, the rains were not severe and did not interrupt project work, however, in 2008, the rains dramatically altered project and recreation plans. In addition, aligning students from UA and Dangriga's junior college to participate is difficult because the junior college semester ends soon after the program summer term begins.

The assessment of the program and projects should examine whether the service actually benefited the community, and should integrate program experience and resources to learn more about the community (DeBlasis, 2006). These community assessments should include ethical considerations (Harshfield et al., 2009) and economic analysis (Jeuland and Whittington, 2009).

The ongoing success of any project depends on how well the project fits the community. This has been recognized and documented for over 40 years under the concept of "appropriate technology," which has now been absorbed into the broader concept of "sustainability." Although we plan and assess "socio-cultural respect" or similar terms, the real motivations and "mental models" of the community are often missed. This remains an ongoing issue in any project and should be recognized (Thornton and Laurin, 2005).

The UA program, "Community Development in a Global Context", has invigorated faculty, changed the lives of students, and impacted the communities. It has been proudly publicized by the UA Honors College with the belief that it can positively impact the UA campus (Johnson, 2009), although it faces ongoing challenges. Hopefully, the program will continue to improve its 
academic rigor, program assessment, community benefits, and sustainability. This program, a part of the Peacework Village Network, is a good model for service-learning programs in developing communities and should be extended to other communities by UA and other universities.

\section{REFERENCES}

Michelle Madsen Camacho, "Power and Privilege: Community Service Learning in Tijuana", Michigan Journal of Community Service Learning, Summer 2004, pp. 31-42.

Amy Lee DeBlasis, "From Revolution to Evolution: Making the Transition from Community Service Learning to Community Based Research", International Journal of Teaching and Learning in Higher Education, Vol. 18, No. 1., pp.36-42, 2006.

Fabrice DeClerck, Jane C Ingram, and Cristina M Rumbaitis del Rio, "The role of ecological theory and practice in poverty alleviation and environmental conservation", Front Ecol Environ 4(10): 533-540, 2006.

John Duffy, "Village Empowerment: Service-Learning with Continuity," International Journal for Service Learning in Engineering, Vol. 3, No. 2, pp. 1-17, Fall 2008.

William Easterly, The White Man's Burden: Why the West's Efforts to Aid the Rest Have Done So Much Ill and So Little Good, (USA: Penguin Press, 2006).

Thomas Eman, "Engineering Education Through Service Learning: Two Case Studies", 2006 ASEE Annual Conference \& Exposition, 18-21 June 2006, 8 pp

Andre de Guillaume, How to Rule the World: A Handbook for the Aspiring Dictator, Chicago Review Press, 144 p., 2003.

Eric Harshfield, Ana Jemec, Ofhani Makhado, and Elias Ramarumo, "Water Purification in Rural South Africa: Ethical Analysis and Reflections on Collaborative Community Engagement Projects in Engineering", International Journal for Service Learning in Engineering, Vol. 4, No. 1, pp. 1-14, Spring 2009.

Gary Hartshorn, Belize: Country Environmental Profile, a Field Study, (Belize City, R. Nicolait \& Associates, 1984), Funded by USAID.

David R. Hokanson, Linda Phillips, and James R. Mihelcic, "Educating Engineers in the Sustainable Futures Model with a Global Perspective: Education, Research \& Diversity Initiatives," International Journal of Engineering Education, 23(2):254-265, 2007.

Ivan Illich, To Hell with Good Intentions, An address by Monsignor Ivan Illich to the Conference on InterAmerican Student Projects (CIASP) in Cuernavaca, Mexico, on April 20, 1968, http://www.swaraj.org/illich_hell.htm 
March Jeuland and Dale Whittington, "Cost-Benefit Comparisons of Investments in Improved Water Supply and Cholera Vaccination Programs", Vaccine, Vol. 27, 2009, pp. 3109-3120.

Peter E. Johnson, "Direct and Indirect Benefits of an International Service-Learning Design Project: Educational Effects on Project Members and Their Peers", International Journal for Service Learning in Engineering, Vol. 4, No. 1, Spring 2009, pp. 15 - 30.

Joseph Kahne and Joel Westheimer "In service of what? The politics of service learning" Phi Delta Kappan, Vol. 77, 1996.

Tracy Kidder, Mountains Beyond Mountains: Healing the World: The Quest of Dr. Paul Farmer, Random House, 2003, 336 pages.

Jennifer R. McConville and James Mihelcic, “Adapting Life Cycle Thinking Tools to Evaluate Project Sustainability in International Water and Sanitation Development Work". Environmental Engineering Science, 24 (7), 2007. pp. 937-948.

James R. Mihelcic, Thomas D. Eatmon, Jr., Ronald A. Harris, and Helen E. Muga, "Engineering Sustainable Construction Materials for the Developing World: A Metadiscipline Approach to Engineering Education," International Journal of Engineering Education, 23(6):1116-11125, 2007.

Kurt Paterson, Linda Phillips, David Watkins, and James Mihelcic, "International Service Engineering across Academic Borders," Conference Proceedings of the American Society for Engineering Education, Chicago, IL, Paper 1098, 10 pages, 2006.

Peacework, Global Partnerships for International Development, http://peacework.org/ 2009

Pearce, J.M, 2006, "Service Learning in Engineering and Science for Sustainable Development", International Journal for Service Learning in Engineering, Vol. 1, No. 1, Spring 2006, pp. $1-4$.

Sachs, J.D. 2005, The End of Poverty: Economic Possibilities for Our Time, Penguin Press.

Thomson, P.A.B., 2005, Belize: A Concise History, MacMillan Caribbean.

Kent Thornton and Christina Laurin, "Soft Sciences and the Hard Reality of Lake Management", Lake and Reservoir Management, 21(2):203-208, 2005.

United Nations Development Program (UNDP), 2006. Human Development Report 2006: Beyond scarcity: Power, poverty and the global water crisis, Report and related materials accessed 1/12/07 at http://hdr.undp.org/hdr2006/report.cfm

Willis Weight, Hydrogeology Field Manual, $2^{\text {nd }}$ Ed., McGraw-Hill, 2008. 


\section{TABLE I}

Example of Writing Assignment

Short answer. Cite references.

-

measured to assess:

$\mathrm{O}$

O

agriculture

$\bullet$

quality study? How?

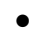

○

○

-

are some other benefits of installing a water system where there was none before?

technology".

American to Mali?

$\bullet$

might involve your discipline? Explain.
○

O

$\bullet$

protected areas in Belize.
What water quality parameters should be

Overall water quality

The impact of

What nutrients are typically measured in a water

What is the analysis cost per sample for

Pesticides

Nutrients

List and describe some water-borne diseases.

Besides prevention of water-borne diseases, what Give a short definition of "appropriate

How many Mali man-hours does it cost to fly an

Which of the UN Millenium Development Goals

What does "sustainability" mean

$$
\text { In general }
$$

In Belize

List and describe the national parks and

- What does "biodiversity" mean in Belize?

- How does working with Billy Barquedier National Park contribute to "development?" 


\section{TABLE II}

\section{Example of Test Questions}

Two-part essay question for engineering team:

1. How does traditional environmental engineering (i.e., water supply and sanitation) fit into community development?

(Explain primary benefits and discuss interactions and synergisms with other aspects of development)

2. How can ecological studies and environmental protection, often considered modern luxuries, fit into community development for poor communities?

Questions:

1.

Name two non-economic and non-technical barriers within a community to the successful implementation of a clean water system in a developing community.

2.

3. an improved water source?
a.
b.
c.

d.

4. Sanitation Development Projects," McConville (2006) identified five factors that projects must incorporate to be successful and sustainable. Which of the following sentences does NOT summarize one of these factors? (i.e., which of the following is not necessarily a part of a successful and sustainable project):

a.

cultural respect.

b. community participation.

c. traditional.

d. be politically cohesive.

e. sustainable.

f. environmentally sustainable.
Give a brief definition of "appropriate technology."

Approximately how many people in the world lack access to
one million
fifty million
one billion

five billion 
d. instinctual knowledge of hygiene and disease transmission and must be taught these things.

e. water develop immunity to it and don't get sick from it.
People are not born with an People who regularly drink unclean

Key:

1. Two of the following: Lack of hygiene knowledge; Tradition; Entrenched attitudes cynicism, entitlement, apathy, dependence, suspicion, over-respect; Political issues 2. Appropriate technology means it is a good fit for the community in all aspects economically affordable, culturally and politically acceptable, able to be constructed, maintained and used.

3. c

4. c

5. e 